\title{
Submitted from BMJ Quality \\ Improving the quality of handover in a liaison psychiatry team
}

\author{
Jennifer Brook, Marilia Amaro Calcia
}

To cite: Brook J, Amaro Calcia M. Improving the quality of handover in a liaison psychiatry team. BMJ Quality Improvement Reports 2016;5:u206492. w3442. doi:10.1136/ bmjquality.u206492.w3442

Received 20 January 2016 Revised 2 May 2016

CrossMark

South London and Maudsley NHS Foundation Trust, UK

Correspondence to Jennifer Brook jennifer. brook@slam.nhs.uk

\section{ABSTRACT}

Handover is a high risk point for errors in clinical care, in many cases leading to adverse events or near misses. The timely transfer of accurate and useful information between professionals is vital to ensure quality and safety, and to ensure the transfer of accountability for care.

In this project standards were developed for quality handover between doctors in a liaison psychiatry department. The aim of these were to ensure adequate identification of patients, clear communication of tasks to be completed and relevant risk issues, as well as a guide to the priority of jobs. We measured compliance with these standards for all patients documented in the handover book during three week periods in 2013, 2014 (following delivery of education and guidance on handover to all doctors), and finally in 2015 after implementation of a proforma for handover.

Handover documentation prior to the implementation of standards was of poor quality with significant absences of information. Key information to identify patients was frequently absent, for example hospital number was only recorded in $1 \%$ of cases. Only $81 \%$ of entries included the reason for the patient's referral, and $27 \%$ made no mention of the outstanding tasks for completion. Despite guidance and education of all doctors regarding the standards, there was no consistent improvement in compliance. It was particularly concerning that risk issues were only mentioned in $18 \%$ of cases, even when assessed immediately after education was given. Following introduction of the proforma compliance increased with overall completeness of handover improving from $40 \%$ to $71 \%$.

Without guidelines handover between shifts is of a poor quality, and often lacks key information to allow colleagues to identify patients and prioritise need. Education of those performing these handovers did not produce any benefits, either immediately following its delivery or in longer term follow up. The implementation of a template to aid clinicians in recording this data did produce improvements and received positive feedback from doctors.

\section{PROBLEM}

King's College Hospital is one of the busiest teaching hospitals in London serving a large inner-city population from the boroughs of Southwark and Lambeth, as well as patients across the south of England who benefit from its tertiary services. The psychiatric liaison service at this hospital is provided by the South London and Maudsley NHS Foundation Trust. Junior doctors working for this trust cover the out-of-hours on call rota for liaison psychiatry, with one junior doctor on call from 5pm to 9am on weekdays, and 24 hours on weekends. In this system, the responsibility for the mental health care of a particular patient at King's College Hospital may be transferred between three doctors within 24 hours, or up to six different doctors within 48 hours. Such a high turnover of clinical responsibility calls for robust systems which ensure no relevant information is lost, and no important tasks are missed.

At the King's College Hospital Psychiatry Liaison service the handover between junior doctors is a face-to-face meeting between the outgoing and the incoming junior doctor. The junior doctor finishing their shift uses the liaison handover book to identify any patients that need to be assessed or reviewed by the junior doctor taking over the shift. For each patient, a handwritten entry will be made in the handover book, containing the necessary identifying information, location of the patient, diagnosis, a brief summary of current concerns, and risks and outstanding tasks.

Prior to the quality improvement project led by the authors, the handover book was a freeform blank book. Entries in the book were very variable in the information recorded and the overall impression was that the quality and usefulness of entries was poor. We also noted a lack of accountability for handover as the clinician writing the entry was rarely identified.

\section{BACKGROUND}

The aim of a handover between shifts is to ensure that all members of the team have the same understanding and priorities with regards to the patients they are looking after (RCS-UK, 2007). The timely transfer of accurate and useful information between professionals ending and starting a shift is 
crucial in ensuring quality and safety of care in all medical specialties. The Royal College of Psychiatrists' Good Psychiatric Practice emphasises the importance of communicating the relevant clinical information to the professionals involved in a patient's care (RCPsych, 2009). It is also important that handover includes only information that is relevant and useful to the assessment and management of a patient at that particular time, as an excess of additional information that has no impact on immediate patient care is likely to "cloud" the picture, making time management and prioritisation of tasks more difficult. Another important aim of a handover is to ensure the transfer of accountability for the care of a patient or group of patients.

Handover is also a high risk point for errors in clinical care, which may lead to adverse events or near misses. Studies of patient safety incidents during handover identified omissions of critical information about the patient's condition or about the patient's care plan during the handover process as some of the root causes of serious incidents and near-misses (Arora 2005, Horwitz 2008). A study of junior doctor handovers in the NHS, using simulated patients, reported a significant gain in information retainment when handover is recorded in a printed handout method, as opposed to being communicated verbally only (Bhabra 2007).

A broad approach to handover quality improvement is necessary, as indicated by a recent study evaluating the effects of the implementation of a bundle of handoverrelated interventions (Starmer 2013). In that study, conducted at a training scheme in Paediatrics, the interventions included not just training and education but also a standardised handover tool. The authors reported a significant reduction in incidents following the intervention without adverse effects to trainee doctors' workflow. While the literature on junior doctors' shift handovers in mental health care is still small, a recent UK-based quality improvement project of shift handover in the mental health care setting using guidelines and flowcharts has reported positive feedback from staff (Perry 2013).

The use of structured and standardised handover tools has been suggested as a way to improve the quality of written handover. A recent review of handover practices in the emergency setting identified a standardised handover tool as one of the areas for improvement in the handover processes (Dawson 2013). Due to the benefits brought by standardised handover tools in improving quality and safety, organisations such as the World Health Organisation, the Academy of Medical Royal Colleges, the Royal College of Physicians, and the British Medical Association have encouraged the use of checklists and handover proformas to improve patient safety (WHO 2007; BMA 2004; RCP 2008).

\section{BASELINE MEASUREMENT}

The process for handover prior to our intervention required clinicians to enter patient details into a blank handover book. We developed a set of criteria for the minimum information required to ensure a safe and effective handover, with a view to ensuring the adequate identification of patients, clear communication of tasks to be completed, and the relevant risk issues, as well as a guide to the priority of given jobs. These were developed based on the expertise of the consultant psychiatrist in the team and our experience of the minimum set of information necessary for safe working in this department. We also sought the opinions of those currently working in the service and adapted the criteria accordingly. These standards were circulated by the consultant psychiatrists at the junior doctors' induction.

Prior to the implementation of our handover pro forma, we collected data from the handover book in use over two separate three-week periods immediately following the new intake of junior doctors. The doctors working in the department would have attended mandatory induction, where guidance on the necessary information for liaison handover was given. For every entry made in the book we recorded whether each item of information in our agreed standards was included. We then calculated the mean completeness of each patient record and also examined the frequency of inclusion/ exclusion for each criterion.

Our baseline measurement was carried out during the first three weeks after the new intake of junior doctors had started their jobs. Though all entries in the book $(\mathrm{n}=87$ entries $)$ contained the patients' names, $14 \%$ did not include their date of birth, $20 \%$ did not include the patient's location within the hospital and only $2 \%$ included the hospital number. Information on risk was only present in $22 \%$ of entries, raising concerns over patient safety. Another issue highlighted was the potential impact of the quality of written handover on the time management and prioritisation of tasks during the shift, given that $90 \%$ of entries did not mention the reason why the referral to psychiatry was made and $87 \%$ did not mention the level of priority of the referral. Fewer than $30 \%$ of entries identified the entering doctor's name.

\section{DESIGN}

Our intervention was carried out in several small stages, using the iterative approach of The Model for Improvement.

Prior to our first PDSA (Plan, Do, Study, Act) cycle we measured the baseline quality and completion of the handover book. Clinicians had previously received only a basic education in the expected standards of handover through a presentation given by the consultant liaison psychiatrist at the junior doctors' induction, at which all clinicians are required to be present. For those doctors working directly in the liaison department, the advice was repeated at their local induction. We audited the handover book for the first three weeks following induction and for a three-week period two months after the 
induction, in October, to ascertain whether the quality of the written handover changed with time.

The aim of our first PDSA (Plan, Do, Study, Act) cycle was improving the clinicians' understanding of what was required from a handover entry. The following year the presentation on the liaison handover at the junior doctors' induction had the new addition of a handout given to junior doctors outlining in more detail the information that needed to be written in the book to ensure a safe handover. We subsequently audited the handover book as we had done for the previous year, i.e. for three weeks in August ( $\mathrm{n}=97$ entries) (after the new intake of junior doctors) and for three weeks in October ( $n=68$ entries). Clinician education via oral and written information did not lead to a significant change in the quality of documented handover content.

It was clear from these results that the doctors required further help in documenting their handover. For our second PDSA cycle we aimed to identify potential causes and develop a tool to help in handover completion. There were two likely causes of the poor documentation identified, time pressures and recalling the various items required. To assist with these we developed a template for the handover book, including some check boxes as well as free-text spaces to speed the process and prompt memory. We discussed this tool with doctors at all grades within the liaison psychiatry team and invited their feedback. We then refined the pro forma using the feedback given to us and developed a new tool. During this cycle, we also gave a presentation to the team on the results of the audits we conducted on the existing handover book, and identified areas where practice was good and areas for improvement.

We implemented the proforma template as a printed sticker to be placed into the liaison handover book. We informed all doctors using the handover book of the implementation via email and face-to-face meetings in the liaison department. We then re-audited the completeness of the handover as before, for three threeweek periods; the first, just after implementation $(n=77$ entries); the second after two months of use ( $n=61$ entries) and the third after nine months of use $(n=75)$.

\section{STRATEGY}

At baseline, prior to the implementation of our developed standards, handover documentation was of poor quality with significant absences of information. Although patients were always identified by name, with $83 \%$ also including a date of birth, their hospital number was only recorded in $1 \%$ of cases. Only $81 \%$ of entries gave the reason for the patient's referral and $27 \%$ made no mention of the outstanding tasks for completion. In only $22 \%$ of cases did the clinician identify themselves.

PDSA cycle 1:

Standards for handover completion were implemented and education regarding these was delivered to all doctors via oral and written information. Following this we re-assessed the quality of handover to determine any impact this had made. Our results showed there was no consistent improvement in compliance. It was particularly concerning that risk issues were only mentioned in $18 \%$ of cases, even when assessed immediately after education about its importance was given.

PDSA cycle 2:

On this cycle, we identified barriers to handover completion and designed a handover pro forma to overcome these. We then implemented the pro forma, initially by pasting printed sheets on the existing handover book. A re-audit of the handover quality following the use of this template showed improvements in most areas, with marked improvements in some such as the use of patient hospital numbers and the identification of the doctor making the handover. Overall handover completeness improved to $71 \%$ in the three-week period immediately after the implementation of the template, maintaining an overall improvement with a completeness rate of $72 \%$ at two months and $78 \%$ at nine months after implementation.

\section{POST-MEASUREMENT}

Following the implementation of the pro forma, data was collected at three points: immediately after implementation; at two months and at nine months after implementation. Data collection used the same methods as the baseline measurement. The results for the baseline measurement and each PDSA cycle are given in table 1 . These are displayed graphically in the bar chart (fig 1).

In addition to this data collection we received positive verbal feedback from doctors using the template that it had been useful. We also conducted an online survey of the junior doctors using the template. Out of those who responded $(n=7), 57 \%$ of trainees found the handover tool easy to use and helpful in identifying patients correctly. All respondents usually spend less than five minutes to complete each entry; and $57 \%$ felt that a handover using a pro forma takes up less time than one without it. $71 \%$ of the respondents found the handover tool useful. In terms of future developments, $57 \%$ of trainees do not believe an electronic handover tool would be useful in our current liaison psychiatry setting, while $28 \%$ feel it may be useful, and $14 \%$ are not sure.

\section{LESSONS AND LIMITATIONS}

This project was run by two junior doctors, with support and supervision by a consultant psychiatrist. As well as improving the quality of handover in our service, the authors were able to develop their skills in team working, organisation, time management, and data analysis. One important lesson for the authors was that relatively simple changes, such as a standardised "checklist" for handover, can lead to significant changes in the working systems, such as shift handover. 
Table 1 Percentage of entries containing each required data point at baseline, following the provision of education and guidance and after implementation of the proforma.

\begin{tabular}{|c|c|c|c|c|c|c|c|}
\hline \multirow[b]{2}{*}{$\begin{array}{l}\text { Item of } \\
\text { information (\%) }\end{array}$} & \multicolumn{2}{|c|}{ With no guidance given } & \multicolumn{2}{|c|}{$\begin{array}{l}\text { With written and verbal } \\
\text { guidance at induction }\end{array}$} & \multirow{2}{*}{$\begin{array}{l}\text { With } \\
\text { proforma } \\
\text { (first } 3 \\
\text { weeks) } \\
\text { February } \\
2015 \text { (n=77 } \\
\text { entries) }\end{array}$} & \multirow{2}{*}{$\begin{array}{l}\text { With } \\
\text { proforma } \\
\text { (after } 2 \\
\text { months) } \\
\text { April } 2015 \\
\text { (n=61 } \\
\text { entries) }\end{array}$} & \multirow{2}{*}{$\begin{array}{l}\text { With } \\
\text { proforma } \\
\text { (after } 9 \\
\text { months) } \\
\text { October } 2015 \\
\text { ( } n=75 \\
\text { entries) }\end{array}$} \\
\hline & $\begin{array}{l}\text { August } \\
2013(n=87 \\
\text { entries) }\end{array}$ & $\begin{array}{l}\text { October } \\
2013(n=111 \\
\text { entries })\end{array}$ & $\begin{array}{l}\text { August } \\
2014(n=97 \\
\text { entries) }\end{array}$ & $\begin{array}{l}\text { October } \\
2014(n=68 \\
\text { entries) }\end{array}$ & & & \\
\hline Name & 100 & 100 & 100 & 100 & 97 & 100 & 99 \\
\hline DOB & 86 & 92 & 60 & 94 & 92 & 90 & 92 \\
\hline Hospital no. & 2 & 0 & 6 & 3 & 34 & 51 & 48 \\
\hline Location & 80 & 87 & 93 & 83 & 89 & 92 & 96 \\
\hline Referrer & 5 & 3 & 4 & 28 & 77 & 78 & 68 \\
\hline Contact no. & 3 & 4 & 3 & 1.5 & 23 & 10 & 9 \\
\hline $\begin{array}{l}\text { Reason for } \\
\text { referral }\end{array}$ & 90 & 86 & 76 & 85 & 94 & 100 & 96 \\
\hline $\begin{array}{l}\text { Whether seen by } \\
\text { psychiatry }\end{array}$ & 34 & 21 & 21 & 28 & 83 & 70 & 83 \\
\hline Priority of task & 13 & 8 & 14 & 3 & 73 & 51 & 59 \\
\hline Risk & 22 & 16 & 18 & 22 & 35 & 42 & 53 \\
\hline Pending tasks & 78 & 79 & 82 & 81 & 91 & 95 & 100 \\
\hline Name of clinician & 29 & 20 & 54 & 19 & 89 & 85 & 97 \\
\hline Signature & 15 & 12 & 6 & 17 & 89 & 80 & 97 \\
\hline $\begin{array}{l}\text { Completeness of } \\
\text { handover }\end{array}$ & 40 & 34 & 38 & 46 & 71 & 72 & 78 \\
\hline
\end{tabular}

Data for this project was collected at several points, and our initial data set showed that traditional educational interventions such as presentations and handouts are of limited value in effecting change in the quality of handover documentation. Though there are still great advantages to face-to-face training at junior doctor induction in other aspects of the job, the analysis of these data showed us that "on the job" interventions such as standardised documentation pro formas can be more effective in making sustained change.
Since the first implementation of our pro forma, we have completed our core training and are now specialist registrars working at the same trust where we initiated the project. The pro forma is still in use and we received positive feedback from the junior doctors in the department. A new handover book has been created, in which the pro forma was printed out and bonded together as a book. This increases efficiency as the junior doctors no longer need to print out additional handover sheets when they run out of them. It is also more
Figure 1 Bar chart showing the percentage of handover entries containing each required data point at baseline, following the provision of education and guidance and after implementation of the proforma.

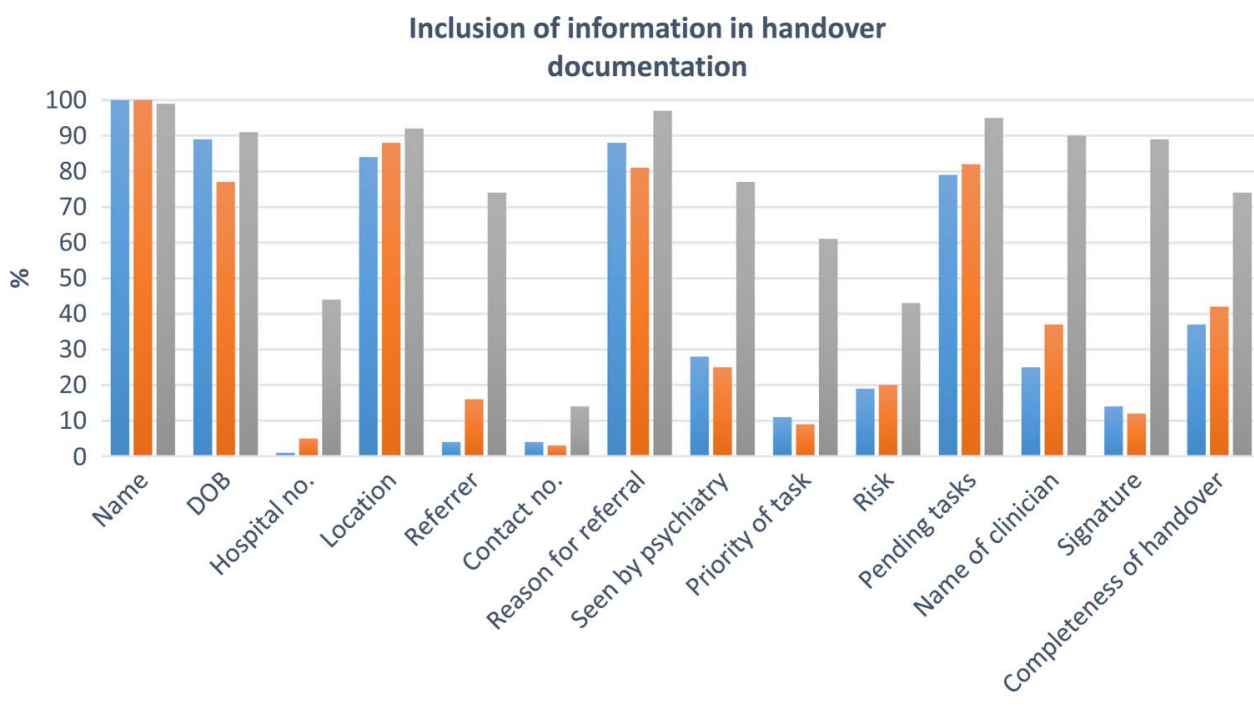

With no guidance With written and verbal guidance with proforma 
environmentally-friendly, as it saves paper compared to the initial intervention, when stickers had to be printed out and pasted onto an existing book. The education delivered at induction by the consultants has also continued.

This project incurred almost no financial cost to the department, as the authors worked in our own time. The only cost associated with the project was the printing of the stickers used initially. The project is likely to have become cost-neutral now as the department has substituted the new printed bundle of handover sheets for the previous blank notebooks.

One of the limitations of our project was the difficulty in studying the effect of the new intervention in patient care. In our trust, it has been shown that doctors are not the most proactive professional group when reporting non-serious incidents or near misses (Baruch 2014, Schectman 2006). Due to the existing systems in place to prevent serious incidents, errors during the handover process may be picked up by the system at different stages, and any near misses are less likely to be reported. This makes it difficult to show whether or not there has been a change to the quality of patient care as a result of this project.

The support of the consultants in the department was vital to the success of this project, as they deliver the induction and lead the handovers. However junior doctor involvement and ownership of the document has been extremely important for its sustainability. This was achieved by consulting doctors during development and incorporating their suggestions into the final pro forma. One of the positive aspects of this project was the good feedback received by the junior doctors. We did not collect baseline data on doctors' satisfaction with the handover system prior to our implementation, but we have now conducted an online survey to collect junior doctors' views on the existing system, particularly with regards to the use of the pro forma. In particular, we wanted to know whether using a pro forma has helped doctors save time and prioritise their referrals during their on call shifts.

\section{CONCLUSION}

Without guidelines and standardised proformas, handover between shifts in our service often lacked key information to allow identification of patients and prioritisation of tasks. Written and verbal information given at induction did not produce significant changes in the quality of handover, even immediately following its delivery. A quality improvement project that resulted in the implementation of a standardised proforma developed by the authors was associated with significant improvement of the quality of the written handover.
Data collected up to nine months after the intervention showed sustained improvement in the quality of handover with the use of a proforma.

Acknowledgements Dr Charlotte Wilson-Jones, Dr Isabel McMullen Declaration of interests Nothing to declare.

Ethical approval According to the policy activities that constitute research at the South London and Maudsley Foundation Trust, this work met criteria for operational improvement activities exempt from ethics review. The proposal was instead reviewed and accepted by the Psychological Medicine Audit committee.

Open Access This is an open-access article distributed under the terms of the Creative Commons Attribution Non-commercial License, which permits use, distribution, and reproduction in any medium, provided the original work is properly cited, the use is non commercial and is otherwise in compliance with the license. See:

- $h t t p: / / c r e a t i v e c o m m o n s . o r g / l i c e n s e s / b y-n c / 2.0 /$

- $\mathrm{http}$ ://creativecommons.org/licenses/by-nc/2.0/legalcode

\section{REFERENCES}

1. The Royal College of Surgeons of England. Safe Handover: Guidance from the Working Time Directive working party. March 2007. Available from: http://www.rcseng.ac.uk/publications/docs/ publication.2007-05-14.3777986999/

2. The Royal College of Psychiatrists. College Report CR154: Good Psychiatric Practice. Third edition, 2009. Available from: http://www. rcpsych.ac.uk/pdf/REVAL2013\%203\%20Good\%20Psychiatric\% 20Practice.pdf

3. Arora V, Johnson J, Lovinger D, Humphrey HJ, Meltzer DO. Communication failures in patient sign-out and suggestions for improvement: a critical incident analysis. Qual Saf Health Care. 2005;14:401-7.

4. Horwitz LI, Moin T, Krumholz HM, Wang L, Bradley EH. Consequences of inadequate sign-out for patient care. Arch Intern Med. 2008;168:1755-60.

5. Bhabra G, Mackeith S, Monterio P, Pothier D. An experimental comparison of handover methods. Ann R Coll Surg Engl 2007;89:298-300

6. Starmer AJ, Sectish TC, Simon DW, et al. Rates of medical errors and preventable adverse events among hospitalized children following implementation of a resident handoff bundle. JAMA 2013;310:2262-70.

7. Perry J, Manghnani R, Sommerlad A, Ikkos G (2013) Improving handovers across a North London Mental Health Trust. BMJ Qual Improv Report 2 (doi: 10.1136/bmjquality.u707.w551)

8. Dawson S, King L, Grantham H. Review article: Improving the hospital clinical handover between paramedics and emergency department staff in the deteriorating patient. Emergency Medicine Australasia 2013;25:393-405.

9. World Health Organisation (WHO) Collaborating Centre for Patient Safety Solutions. Communication during patient handovers. Patient Safety Solutions, vol. 1, solution 3, May 2007. Available from: http:// www.who.int/patientsafety/solutions/patientsafety/PS-Solution3.pdf

10. British Medical Association (2004). Safe Handover, Safe Patients. Guidance on clinical handover for clinicians and managers. London: British Medical Association. Available from: www.bma.org.uk/ employmentandcontracts/employmentcontracts/junior_doctors/ Handover.jsp

11. Royal College of Physicians (2008) A Clinician's Guide to Record Standards - Part 2: Standards for the structure and content of medical records and communications when patients are admitted to hospital. Available from: https://www.rcoa.ac.uk/sites/default/files/ FPM-clinicians-guide2.pdf

12. Baruch N. Adverse incidents and patient safety- improving the learning experience of junior doctors. Clin Med 2014. 14:42-3.

13. Schectman JM, Plews-Ogan ML, Physician perception of hospital safety and barriers to incident reporting. Jt Comm J Qual Patient Saf 2006;32:337-43. 